\title{
PENGHIJRAHAN DAN
}

\section{PENCARIAN IDENTITI MELAYU PATANI DIASPORA DALAM CERPEN ISMA AE MOHAMAD}

(Migration and the Search for Diasporic Patani Malay Identity in Isma Ae Mohamad's Short Stories)

Mohamed Nazreen Shahul Hamid

mohamednazreen25@gmail.com

Muhammad Izzat Md Isa

Md. Salleh Yaapar

mdsalleh@usm.my

Pusat Pengajian Ilmu Kemanusiaan, Universiti Sains Malaysia, Malaysia.

\begin{abstract}
Abstrak
Pengarang Melayu Patani yang berhijrah ke Malaysia membentuk identiti mereka berasaskan keadaan diaspora. Kebanyakan karya mereka tertumpu pada genre sajak dan cerpen. Antara pengarang yang menonjol ialah Isma Ae Mohamad yang banyak menghasilkan cerpen. Makalah ini bertujuan menganalisis cerpen terpilih Isma Ae Mohamad dengan tumpuan pada krisis budaya dan pencarian identiti wataknya. Cerpen yang dimaksudkan ialah "Ke Negeri Impian", "Perjalanan ke Sebelah Sana", "Gadis Tomyam” dan "Rindu Cerita Nenek". Karya pengarang diaspora ini dikaji berpandukan kerangka konseptual kajian diaspora oleh Regina Lee. Kajian ini mendapati karya Isma Ae Mohamad memenuhi tiga pola diaspora, iaitu sanjungan terhadap tanah air, manifestasi butik multibudaya, dan politik identiti transisi. Malah, karya beliau juga jelas menonjolkan krisis budaya dan pencarian identiti. Pelbagai pengalaman masyarakat diaspora diungkapkan terutama tentang masalah pendidikan dan kerakyatan. Secara keseluruhan, cerpen ini memperlihatkan pandangan orang Patani yang berdiaspora tentang masa lalu dan masa kini dalam kehidupan mereka. Penemuan kajian ini adalah penting
\end{abstract}


kerana hasilnya dapat menyumbang ke arah memahami nasib diaspora Patani dan krisis identiti yang mereka hadapi.

Kata kunci: Melayu Patani, diaspora, penghijrahan, pencarian, identiti

\begin{abstract}
Malay Patani authors who have migrated to Malaysia form their identities based on diasporic conditions. Most of their works focus on the genre of novels and short stories. Among the prominent authors is Isma Ae Mohamad who has produced many short stories. This paper aims to analyse the short stories of Isma Ae Mohamad by focusing on the cultural crisis and the search for identity faced by his characters. The short stories comprise "Cerita Dari Sempadan”, "Ke Negeri Impian”, "Perjalanan Ke Sebelah Sana”, "Gadis Tomyam", and "Rindu Cerita Nenek". The diasporic author's works are analysed based on the conceptual framework of diaspora studies proposed by Regina Lee. This study finds that the works of Isma Ae Mohamad fulfil the three proposed diaspora patterns, namely, the idealisation of the homeland, manifestation of boutique multiculturalism, and identity politics in transition. In fact, his works also clearly illustrate the phenomena of cultural crisis and the search for identity. Various experiences of the diasporic community are expressed primarily on issues pertaining to education and citizenship. Overall, these short stories reflect the views of the diasporic community of Patani towards their past and the present of their lives. Findings of this study are important as the results can contribute towards the understanding of the fate of the diasporic Patanis and the crisis of identity that they face.
\end{abstract}

Keywords: Malay Patani, diaspora, migration, search for identity

\title{
PENDAHULUAN
}

Konflik di wilayah Patani atau Selatan Thailand bukan satu perkara baharu kerana keadaan ini telah berlaku sejak zaman kesultanan Melayu Patani, dan berterusan sehingga kini. Pada era kolonialisme berkuasa, telah berlaku perebutan kawasan dan perluasan kuasa di seluruh Asia Tenggara antara British, Perancis, Belanda, Sepanyol, Amerika Syarikat dan Jepun. Pelbagai perjanjian telah dimeterai dalam mencipta sempadan politik bagi mengawal pengaruh masing-masing. Salah satu daripadanya ialah Perjanjian Bangkok pada 1909 antara kerajaan British dengan Siam yang telah meletakkan Patani secara kekal sebagai "the Siamese Malay State" (Nik Anuar 2011, hlm. 29). Perkara ini bukannya atas pilihan penduduk tempatan. Malangnya, 
bermula dari detik itu Patani terpaksa melalui sejarah pahit perjuangan berdarah setelah berada di bawah pemerintahan Bangkok. Pemecahan kawasan oleh kuasa kolonial tersebut telah mewujudkan sempadan baharu, dan meneruskan konflik di wilayah Patani.

Konflik yang berlaku antara masyarakat Melayu Patani dengan pihak pemerintah Thailand bukan sahaja menimbulkan ketegangan, malah menyebabkan pertumpahan darah yang kemuncaknya dikatakan pada tahun 2004, iaitu peristiwa berdarah di Masjid Krisek dan pembunuhan beramairamai di Tabal atau Tak Bai. Kedua-dua peristiwa tersebut telah menarik perhatian dunia terhadap realiti yang berlaku di Selatan Thai. Kesan konflik yang berpanjangan ini turut membawa proses penghijrahan penduduk Patani ke pelbagai tempat lain. Proses ini telah mewujudkan masyarakat Melayu Patani diaspora dan menjadi perhatian Isma Ae Mohamad dalam penulisan cerpennya. Hal ini demikian kerana, sastera tidak dapat dipisahkan daripada pengarang dan masyarakat. Kejadian di persekitaran memberikan kesan dan ilham kepada pengarang, justeru dialirkan dalam bentuk karya kreatif.

Dengan latar maklumat seperti di atas, kajian ini akan memberikan tumpuan pada cerpen terpilih Isma Ae Mohamad dalam menganalisis permasalahan berkaitan dengan penghijrahan dan pencarian identiti Melayu Patani diaspora. Sebagai pengarang muda kelahiran Patani yang menulis dalam bahasa Melayu, cerpen beliau kelihatan terkesan dengan keadaan masyarakat di kawasan konflik terbabit. Isma Ae Mohamad kini telah menetap di Malaysia. Penghijrahan beliau merupakan suatu proses kehidupan diaspora, lalu dialirkan pengalaman hidup itu melalui pena dan persuratan. Karya beliau ini wajar dianalisis berdasarkan pengalaman hidup beliau sebagai penulis Melayu Patani diaspora.

\section{KERANGKA KONSEPTUAL: MEMAHAMI PERKAITAN DIASPORA DAN SASTERA}

Secara asasnya, perkataan diaspora berasal daripada perkataan Yunani kuno, iaitu diaspeirein yang membawa maksud berselerak. Menurut International Encyclopedia of Social Science (S.S Shashi, 2007, hlm. 1331) diaspora merujuk "nation or part of a nation separated from its national territory, but preserving its national identity while scattered among other peoples". Maknanya, diaspora pada umumnya merujuk bangsa yang terpisah dari wilayah asalnya, bertaburan di tempat lain, tetapi masih lagi memelihara identiti asal mereka. Pada awalnya, pemaknaan diaspora sering dikaitkan 
dengan pemaksaan sesuatu etnik untuk keluar dari tempat asal. Perkara ini ada dinyatakan oleh Dictionary of Race, Ethnicity and Culture (2003, hlm. 73), iaitu diaspora menyarankan "a particular type of journey, one usually involving some degree of compulsion". Maka, diaspora kerap kali dilihat sebagai orang yang "tinggal dalam buangan". Kini istilah diaspora digunakan untuk menggambarkan pengalaman pergerakan atau taburan sesebuah masyarakat. Kajian diaspora pula sering menganalisis impak sosial, budaya dan formasi politik yang berlaku akibat pergerakan dan taburan tersebut.

Seperti subjek yang lain, diaspora juga dikaji oleh ramai sarjana. Namun, antara tokoh yang sering dikaitkan dengan pengkajian diaspora ialah Robin Cohen (1997, hlm. 13) yang menegaskan bahawa seseorang diaspora jati akan menunjukkan dirinya sentiasa berhubung dengan sejarah imigrasi dan masih mengekalkan semangat kekitaan sesama golongan etnik yang sama latar belakangnya. Selain itu, Cohen turut menyenaraikan panduan asas manusia diaspora berdasarkan kepada beberapa ciri umum, iaitu:

(1) Dispersal from an original homeland, often traumatically, to two or more foreign regions.

(2) Alternatively, the expansion from a homeland in search of work, in pursuit of trade or to further colonial ambitions.

(3) A collective memory and myth about homeland including its location, history and achievements.

(4) An idealization of the putative ancestral home and a collective commitment to its maintenance, restoration, safety and prosperity, even to its creation.

(5) The development of a return movement which gains collective approbation.

(6) A strong ethnic group consciousness sustained over a long time and based on a sense of distinctiveness, a common history and the belief in a common fate.

(7) A troubled relationship with host societies suggesting a lack of acceptance at the least or the possibility that another calamity might befall the group.

(8) A sense of empathy and solidarity yet creative and enriching life in host countries with a tolerance for pluralism. 
Berdasarkan ciri-ciri umum diaspora yang dinyatakan oleh Cohen ini dapat disimpulkan bahawa golongan diaspora terpisah dari tanah asal, sentiasa berada dalam keadaan trauma dan mempunyai sebab tertentu untuk berhijrah, umpamanya kerana peluang pekerjaan, faktor penjajahan dan sebagainya. Namun, golongan ini tetap terikat dengan tempat asal atau tanah air melalui ingatan, kerinduan dan sejarah. Malah, manusia diaspora ini juga akan membentuk komunitinya dengan penuh solidariti, tetapi bertoleransi terhadap pluralisme. Walau bagaimanapun, akan timbul masalah daripada bentuk hubungan antara mereka dengan masyarakat di tempat baharu, iaitu masyarakat peribumi atau tuan rumah terutamanya dari aspek penerimaan.

Masyarakat diaspora mempunyai corak kehidupan tersendiri dan agak istimewa jika difahami dalam bentuk penulisan sastera. "Keistimewaan" pengalaman dan budayanya sentiasa menjadi perangsang kepada pengarang diaspora untuk meluahkannya dalam bentuk penulisan. Spivak (2012) ada menyatakan bahawa:

From this perspective, I have come to ask: what is it about the migration that makes migrants and non-migrants want to write and read about it? Is seems to me that a prime attraction is the emblematic quality of the migration experience. The movement of protagonists through space and time and across cultures and landscapes, offers writers a means to distil, contain and apply narrative structure to the human life span in all its messy complexity-without sacrificing any ingredients. The migrant experience provides the dramatic forum to explore the fundamental themes of literature; the interaction between self and society, the complexity of identity, the comfort of the familiar, and the attraction and fear of the strange. As anyone who has migrated themselves knows, migration is life writ large. It makes protagonists of us all. ${ }^{1}$

Spivak menganggap pengalaman penghijrahan yang dialami oleh pengarang sebagai suatu aset yang berkualiti dalam menghasilkan karya yang menarik. Pengalaman ini dizahirkan oleh pengarang melalui pembinaan plot dan pergerakan watak melalui latar masa, ruang dan budaya. Selain itu, pengalaman tersebut juga telah memudahkan pengarang untuk menerokai tema asas kesusasteraan, seperti interaksi antara diri dan masyarakat, kerumitan identiti, gangguan fikiran dan sebagainya yang sering dialami oleh manusia diaspora. Keperihalan ini dianggap sebagai satu keistimewaan yang wujud pada pengarang diaspora dan diadunkan untuk menonjolkan sisi positif terhadap etnik diaspora. 
Selain itu, pertautan yang erat antara pengarang dan pengalamannya menjadikan karya sastera seakan-akan karya autobiografi dan dokumen sosial kerana segala pengalaman hidup penghijrah dialirkan dalam penulisan. Biasanya karya yang bersifat autobiografi segera menyarankan bahawa penulisan tersebut pada pokoknya berdasarkan kepada kisah hidup sebenar pengarangnya (Ali Ahmad, 1994, hlm. 67). Tema pengarang diaspora selalunya hampir sama tidak kira etnik diaspora apa pun dan dari mana bahagian dunia. Hal ini dikatakan demikian kerana, pengarang diaspora selalunya akan mengungkapkan tema atau isu berdasarkan pengalaman dan persekitaran mereka sebagai penghijrah. Menurut Thirumamani (2006, hlm. 23), kesusasteraan diaspora memperkatakan hasil karya imigran yang melibatkan persoalan seperti identiti, budaya, sifat unik etnik, kewarganegaraan, asimilasi budaya, integrasi dan persoalan lain tentang masyarakat tersebut. Topik ini mendapat perhatian pengarang diaspora kerana isu ini menjadi faktor yang mencorakkan kehidupan etnik diaspora di perantauan.

Pengarang diaspora sering kali menghasilkan karya berdasarkan pemerhatian dan perasaan terhadap iklim yang wujud di dua tempat, iaitu tempat asal dan tempat baharu atau lokasi penghijrahan. Karya yang memperlihatkan tempat asal atau tanah air sering berkaitan dengan keagungan dan kehebatan ketamadunannya serta ingatan lampau yang mengusik kerinduannya terhadap tempat asal. Di tempat baharu, pengarang lebih menjurus pada persoalan rintangan dan cabaran apabila berada di perantauan. Latar persoalan ini juga bergantung pada tahap generasi diaspora melihat persekitaran. Generasi pertama diaspora sering kali melihat isu berkaitan tarikan ekonomi, manakala generasi terkemudian lebih terarah kepada isu kerakyatan dan kelangsungan pengekalan identiti dan budaya.

Berasaskan perbincangan di atas, maka dalam penganalisisan penghijrahan dan pencarian identiti Melayu Patani diaspora dalam cerpen Isma Ae Mohamad, pola diaspora yang dicetuskan oleh seorang lagi sarjana, iaitu Regina Lee, akan digunakan. Lee (2004, hlm. 54) telah menggariskan tiga pola asas diaspora iaitu:

(1) Sanjungan terhadap tanah air (idealization of homeland).

(2) Manifestasi butik multi-budaya (boutique multicultural manifestation).

(3) Politik identiti transisi (transitional/transformational identity politics). 
Pola sanjungan terhadap tanah air merupakan salah satu motivasi yang paling kuat mendorong masyarakat diaspora. Kepercayaan pada tempat asal yang membantu memberikan keyakinan kepada penghijrah untuk sentiasa melihat ke belakang dan sejarah silamnya tanpa mengira perbezaan geografi, budaya dan masalah fizikal. Prinsip manifestasi butik multibudaya atau boutique multicultural manifestation pula merujuk keadaan masyarakat yang menjadi majmuk apabila berlakunya proses campur aduk pelbagai budaya yang dibawa oleh penghijrah dan masyarakat setempat. Kemajmukan masyarakat kini dilihat sebagai satu kenyataan hidup di kebanyakan negara dan melahirkan dunia globalisasi. Kemunculan kelompok diaspora akan membentuk kaum minoriti dan akan terbentuk sistem kelas yang dikenali sebagai "simbol status" berasaskan etnik dan bangsa. Pola politik identiti transisi pula merujuk persoalan transformasi atau pembentukan identiti transisi, terutamanya kepada generasi diaspora yang terkemudian. Selepas generasi pertama, penghubung dengan tempat asal akan mulai renggang dan potensi perubahan tersebut akan membentuk jati diri sementara di tempat baharu. Masa akan menjadi ruang kepada pembentukan generasi diaspora hibrid. Generasi diaspora baharu ini akan turut membentuk perpaduan dalam komuniti mereka melalui kesatuan politik. Ketiga-tiga pola ini merupakan motivasi yang kuat terhadap tingkah laku masyarakat diaspora. Ketiga-tiga pola asas diaspora yang dikemukakan oleh Lee ini mempunyai bentuk yang ringkas, padat dan bersifat umum. Pola yang dikemukakan beliau juga boleh disesuaikan dengan pelbagai keadaan individu mahupun kelompok masyarakat diaspora.

\section{ANALISIS TEKSTUAL}

Analisis terhadap cerpen Isma Ae Mohamad yang dilakukan adalah melibatkan dua aspek utama, iaitu penghijrahan dan pencarian identiti masyarakat Melayu Patani diaspora.

\section{Penghijrahan Masyarakat Melayu Patani Diaspora}

Diaspora masyarakat Melayu Patani ke Malaysia bersifat sukarela dan terpaksa. Sukarela kerana faktor individu itu sendiri yang membawa diri untuk berpindah ke tempat lain, manakala terpaksa pula merujuk keadaan tertentu seperti tekanan politik oleh pihak pemerintah dan desakan ekonomi yang memaksa mereka untuk berhijrah. Diaspora dari Patani ke Malaysia lebih mendekati bentuk migrasi dalaman sahaja, iaitu berhijrah ke satu 
tempat yang mengamalkan kebudayaan yang sama. Misalnya, penghijrahan orang dari Pulau Sumatera seperti orang Kampar, Minang, Mandailing dan lain-lain dari rumpun Melayu ke Semenanjung Tanah Melayu zaman dahulu. Meskipun begitu, wujud variasi terhadap punca diaspora oleh masyarakat Melayu Patani untuk ke Malaysia masa kini. Perihal ini ada dijelmakan dalam cerpen Isma Ae Mohamad. Contohnya, dalam cerpen "Rindu Cerita Nenek" (2013, hlm. 48) telah diperlihatkan oleh pengarang bahawa penghijrahan watak "ayah" ke tanah sempadan berlaku kerana masalah politik yang berkaitan dengan perjuangan terhadap penjajah Thai:

Aku cucunya dari anak lelakinya yang membawa diri ke Malaysia dan tak pulang-pulang. Daripada cerita nenek aku tahu cerita sebenar pasal ayah. "Ayahmu memilih untuk memisahkan diri, membawa diri ke Malaysia setelah kecewa dengan perjuangan dan barisan pemimpin pejuang kemerdekaan.

Melalui petikan di atas dapat dilihat bahawa wujud permasalahan dalam kumpulan pejuang kemerdekaan di Patani yang membawa kepada berlakunya diaspora terhadap ahli-ahlinya. Pengarang mungkin cuba mengaitkan dengan situasi sebenar yang berlaku terhadap kumpulan pejuang kemerdekaan yang berada di Patani sekarang seperti Barisan Revolusi Nasional (BRN), Patani United Liberation Organisation (PULO) ${ }^{2}$ dan sebagainya.

Faktor ekonomi turut menjadi dorongan kepada masyarakat Melayu Patani melakukan diaspora ke negara bangsa serumpun di sempadan, iaitu demi mencari kehidupan yang lebih baik. Dalam cerpen "Ke Negeri Impian" digambarkan watak "ayah" yang tekad hendak berhijrah ke Malaysia meskipun telah dipujuk oleh kakaknya untuk kekal tinggal di Patani:

Suara emak saudaranya seakan-akan memujuk bersuara di luar, "Dok rok duk Malay. Bukan senang tinggal di Malaysia". Diam sejenak. Di sini pun, ikan, udang, ketam sedang menunggu kita. Ayahnya diam membisu. Ayah nekad ke negeri impian. ${ }^{3}$

Keadaan ini berlaku kerana pembangunan ekonomi di Patani atau Selatan Thailand tidak serancak seperti di bahagian Utara Thailand kerana pergolakan senjata yang sentiasa berlaku. Tambahan pula, pihak kerajaan Thailand tidak fokus dalam membangunkan aktiviti ekonomi di Selatan Thailand kerana bimbang akan kemajuan yang dicapai nanti bakal menggalakkan pemberontakan yang lebih besar. Akibatnya, tidak wujud pelbagai tawaran pekerjaan terhadap masyarakat Melayu Patani, terutamanya bagi generasi 
muda yang berkelulusan tinggi dalam pendidikan. Maka, masyarakat Melayu Patani terus berada dalam keadaan mundur dan sentiasa melihat Malaysia sebagai "negeri impian" yang mampu mengubah taraf ekonomi dan hidup mereka.

Dari sudut sejarahnya, Patani ialah negeri orang Melayu. Patani merupakan salah sebuah negeri daripada negeri-negeri Melayu di Kepulauan Melayu. Hubungan dengan negeri Melayu lain sudah lama terjalin dan tidak pernah terputus, misalnya melalui hubungan persaudaraan, terutamanya dengan negeri Kedah, Kelantan dan Terengganu. Maka, penghijrahan masyarakat Melayu Patani ke Malaysia tidak menjadi satu perkara yang aneh, walaupun persempadanan politik moden terbentuk antara negara Thailand dan Malaysia. Malah, hubungan persaudaraan ini terus menjadi faktor yang menggalakkan diaspora Melayu Patani ke Malaysia. Isma Ae Mohamad dalam cerpen "Perjalanan ke Sebelah Sana" (2011, hlm. 79) merasakan keadaan ini berlaku kerana hubungan rumpun Melayu tidak sedikit pun terjejas melalui persempadanan negara di bawah penjajah Thai:

Dari percakapan dengan makcik ini dapat difahami bahawa perhubungan wilayah ini dengan wilayah-wilayah Melayu merdeka tidak pernah putus oleh sempadan antarabangsa.

Meskipun, setiap individu mempunyai sebab tertentu dalam melakukan diaspora tetapi dapat dilihat bahawa hubungan persaudaraan antara negerinegeri Melayu yang ada sentiasa menjadi motivasi kuat untuk mereka berhijrah.

Setelah melakukan diaspora, masyarakat Melayu Patani, seperti diaspora yang lain, akan hidup dalam keadaan tertentu. Misalnya, pengalaman diaspora oleh generasi pertama akan sentiasa diingatkan kepada generasi kemudian agar diambil sebagai iktibar. Malah, generasi terkemudian juga turut diajar untuk tidak melupakan sejarah silam. Watak "aku" dalam cerpen "Perjalanan ke Sebelah Sana" (2011, hlm. 78), misalnya, diingatkan tentang asal usul dan bangsanya seperti berikut:

Sebentar, terasa tangan ibu datang mengusap-ngusap di kepala. "Baca buku ini. Kamu akan faham mengapa ayah begitu garang sekali tadi". Ibu menghulur sebuah buku lusuh bertulis jawi. Saya menatap, 'Sejarah Kerajaan Melayu Patani' yang ditulis Ibrahim Syukri. Semalaman, saya membaca habis buku itu.

Walaupun menetap di luar Patani, masyarakat diasporanya tetap mengambil tahu akan setiap perkembangan yang berlaku di Patani, 
terutamanya isu konflik dan pergolakan yang berkaitan. Misalnya, watak "ayah" yang sentiasa mengambil berat perkembangan di Selatan Thailand dalam "Perjalanan ke Sebelah Sana" (2011, hlm. 78):

Hinggalah, satu malam, saya sudah sekolah menengah ketika itu, kami duduk menonton berita. "Apalah, bodoh betul. Nak merdeka? Tapi senjata tak ada. Sepatutnya mereka bangga hidup di negara yang tidak pernah dijajah kuasa asing". "Diam! Apa kau tahu!?" Suara ayah keras membentak setelah reaksi spontan saya bila berita pergolakan di Selatan Thai dikhabarkan. Semua diam. Hanya suara wartawan TV3 Azura Zainal Ratin jelas di udara. Saya jadi terketar-ketar, kecut perut, Ayah bangun, dan keluar rumah dengan menghempas pintu.

Begitulah, sejarah tempat asal sentiasa diingatkan kepada generasi baharu agar sejarah tersebut tidak dilupakan dan sentiasa diberikan kefahaman terhadap perkembangan terkini yang berlaku di tanah air.

Apabila berada di tempat yang baharu, seseorang diaspora itu akan mula terkenangkan tanah airnya, terutama tentang kegemilangan, kecemerlangan dan keunggulan ketamadunan lampaunya. Hal ini bertepatan dengan idea yang dikemukakan oleh Lee tentang pola diaspora berkaitan sanjungan terhadap tanah air (idealization of homeland). Penghijrah akan memandang ke belakang dan menghargai sejarah silam bangsanya dan secara tidak langsung menambahkan keyakinan tentang asal usulnya. Patani mempunyai sejarah peradaban yang tinggi, dengan kemuncaknya ketika zaman pemerintahan Ratu-ratu Patani, iaitu Ratu Hijau, Ratu Biru, Ratu Ungu dan Ratu Kuning. Pengarang diaspora seperti Isma Ae Mohamad tidak terkecuali daripada mengingati sejarah kehebatan bangsanya ini. Misalnya, telah dinukilkan seperti berikut oleh pengarang dalam cerpen "Perjalanan ke Sebelah Sana" (2011, hlm. 81):

Duduk termenung dalam masjid, mengamati lapisan batu-batu merah yang membangunkannya. Saya percaya masjid ini sebuah masjid yang sudah siap di zaman Raja-raja perempuan Patani memerintah lagi. Ia sebuah masjid raya yang menjadi tempat ilmu disebarkan, dan tempat perpaduan ummah serta simbol kedaulatan negeri ini ketika itu.

Generasi muda Patani turut mengingati keagungan Patani melalui cerita lisan yang disampaikan secara turun-temurun. Contohnya, melalui cerpen "Rindu Cerita Nenek" (2013, hlm. 46) pengarang menggambarkan watak 
"aku" yang sentiasa mengingati cerita sejarah yang disampaikan oleh neneknya. Watak nenek ada menceritakan peristiwa kedatangan Islam di Patani:

Suaranya, turun-naik nada penceritaannya seperti aku mendengar nenek mencerita kisah mula negeri Patani Darulsalam memperoleh nur Islam suatu ketika dahulu. Nenek menarik nafas, matanya berair, begini mulanya Islam masuk ke Istana Negara Patani ... Pada suatu hari, seisi istana dikejutkan dengan raja mengaduh kesakitan..." Tuanku bomoh Siam sudah dipanggil, pawang Melayu pun sudah, juga dukun Khmer tapi semuanya masih gagal. Apa kata dipanggil orang Arab berjubah di kampung Pasai itu? Khabarnya orang Arab berjubah itu pandai ubat mengubat ..."

Selain itu, generasi Patani diaspora juga turut dikhabarkan tentang kehebatan Patani dalam aspek pertahanan yang menjadi kebanggaan rakyat Patani. Watak nenek menceritakan sejarah Lim Toh Khiam yang mahir membuat meriam dalam cerpen "Rindu Cerita Nenek" (2013, hlm. 48):

... aku membayangkan Lim Toh Khiam yang teguh iman. Lalu mendengar nenek bercerita. Lim Toh Khiam asalnya seorang lanun tetapi akhirnya dia insaf dan terdampar di negeri Patani, seterusnya memeluk agam Islam dengan nama Yaakob ... Kepandaiannya menghasilkan tiga buah meriam besar dan hebat untuk Patani menjadikan Tok Khiam tiba-tiba disebut-sebut orang. Dari mulut perisik Siam hinggalah ke telinga Raja Ayutthaya ...

Oleh itu, dapat dinyatakan bahawa sejarah keagungan tempat asal sentiasa mengiringi individu diaspora, dan bagi pengarang topik ini akan dinukilkan dengan pelbagai cara dalam karya yang terhasil.

Masyarakat Melayu Patani diaspora yang berada di Malaysia sentiasa bersyukur dengan keharmonian yang dapat dikekalkan di sini. Meskipun berada dalam keadaan diaspora nasib mereka kelihatan lebih baik daripada mereka yang berada di tanah asal. Gambaran kesyukuran ini terpancar dalam cerpen "Perjalanan ke Sebelah Sana" (2011, hlm. 81), iaitu:

\footnotetext{
Alhamdulillah, saat kaki saya menjejak tangga naik ke jeti imigresen Pengkalan Kubur, dada terasa lapang, luas, menyedut udara di bumi merdeka. Sungguh, saya bertuah. Bila saya berpaling ke belakang, menatap jauh-jauh ke sebelah sana, kelihatan bendera berjalur merah, biru dan putih berkibar-kibar megah ketika matahari mula terbenam. Lewat mata batin ini, bendera itu nampak koyak-koyak.
} 
Untuk nukilan itu, pengarang telah menggunakan unsur perlambangan dalam menggambarkan perasaannya. Perlambangan yang dimaksudkan adalah terhadap bendera Thailand, iaitu melalui pancaindera nampak cantik dan megah tetapi jauh di sudut hati bendera tersebut kelihatan koyak rabak. Hal ini demikian kerana, kemegahan tersebut tidak dapat menandingi pengalaman penderitaan dan kesengsaraan akibat kekejaman dan penindasan pihak penjajah Thailand terhadap rakyat Patani selama ini. Kemegahan tersebut tiada nilainya jika tiada wujud kebebasan dan keamanan yang di kecapi oleh rakyat Patani yang merupakan rakyat negaranya juga.

\section{Pencarian Identiti Masyarakat Melayu Patani Diaspora}

Di Malaysia, masyarakat Melayu Patani diaspora tidak menghadapi masalah dalam mengekalkan identiti Melayu Patani daripada diasimilasi budaya secara paksaan seperti yang berlaku di Thailand. Contohnya, bahasa Melayu di Thailand dipinggirkan dan mereka dipaksa untuk menguasai bahasa Thai yang perlu diterima sebagai bahasa kebangsaan. Namun, kelompok ini mempunyai masalah dalam proses pembinaan identiti baru yang berasaskan identiti asal Melayu Patani. Hal ini demikian kerana, mereka dipandang serong oleh masyarakat tempatan atas sebab-sebab tertentu. Misalnya, wujudnya status pendatang atau pelarian politik/ekonomi/sosial kepada mereka, tidak pandai bercakap dalam bahasa Melayu Malaysia, dianggap sedikit mundur, kurang mahir berbahasa Inggeris dan lain-lain lagi. Situasi ini membawa kepada sifat rendah diri dan kurang keyakinan pada masyarakat Melayu Patani diaspora. Perasaan ini dinukilkan Isma Ae Mohamad dalam cerpen "Ke Negeri Impian" (2012):

"Esok masuk sekolah, berhati-hati bila berkecek, jangan kecek macam orang Tani, cuba kecek macam orang Kelate. Kalau tak, orang sini akan pandang rendah pada kita". Beberapa tahun kemudian barulah dia faham betapa orang Patani atau orang Melayu sebelah Siam dianggap orang Melayu kelas kedua di sini mengikut persepsinya. ${ }^{4}$

Melalui pesanan ibu kepada anaknya dalam petikan tersebut jelas bahawa dialek Melayu Patani jika digunakan di sini akan menyebabkan mereka di pandang rendah. Dialek Melayu Kelantan harus digunakan agar dapat meletakkan diri setaraf dengan masyarakat tempatan. Keadaan ini secara tidak langsung menyebabkan masyarakat Melayu Patani merasakan diri mereka sebagai orang Melayu kelas kedua. 
Pandangan serong orang tempatan menyebabkan golongan ini menerima tekanan. Bentuk krisis identiti seperti ini sebenarnya sering kali berlaku kepada mana-mana masyarakat diaspora di dunia. Isma Ae Mohamad menggambarkan situasi tersebut melalui watak Nuriya dalam cerpen "Gadis Tomyam" (2012, hlm. 85):

Dia hanya ada gelar daripada orang sekelilingnya, iaitu orang sebelah Siam. Nuriya sukar menerima hakikat akan gelar itu. Sejak dia bersekolah rendah lagi, dia sering diejek dengan pelbagai gelar-anak pendatang, PATI Golok dan anak sungai Golok. Itu beberapa contoh yang dia ingat. Terlalu sukar baginya, meskipun dia sedar hakikat yang dia dilahir sebuah kampung Melayu di kuala Bekah berdekatan dengan kuala sungai Patani, Thailand.

Gelaran yang diberikan telah mengganggu emosi mereka. Masyarakat Melayu Patani diaspora menerima kesan psikologi apabila sering disentuh tentang status identiti mereka. Watak Nuriya sentiasa merasakan istilah "pendatang" sebagai kata larangan (taboo). Pengarang menulis lagi dalam "Gadis Tomyam" (2012, hlm. 85) seperti petikan di bawah:

"Ketika kerajaan sedang berusaha membasmi kehadiran pendatang asing, saya tidak berbuat demikian. Saya mengalu-ngalu kedatangan mereka. Di sekolah kita tahun ini, saya menerima seorang pendatang", kata pengetua di perhimpunan mingguan. Pedih hati Nuriya mendengar. Dia membenci perhimpunan mingguan sekolah sejak itu sampai tamat sekolah. Meskipun pengetua tak pernah menyebutnya lagi di perhimpunan mingguan, hanya sekali itu. Setelah itu para pelajar dan guru tertanya-tanya. Mulanya hanya pengetua dan kerani sekolah sahaja yang tahu akan statusnya. Ia tidak lama. Identiti dirinya pecah. Dari saat it, Nuriya selalu ditanya soalan tentang statusnya, "sudah dapat kad pengenalan?" oleh guru atau sesiapa sahaja dalam banyak pertemuan dengannya.

Maka, dapat dilihat persepsi masyarakat Melayu di Malaysia dan kesannya terhadap diaspora Patani terutamanya dari aspek psikologi. Sebenarnya hal ini perkara biasa untuk semua pendatang di mana-mana negara pun. Cuma, sebagai orang berbangsa Melayu, masyarakat Melayu Patani amat berharap mereka diterima sepenuhnya oleh masyarakat dan negara Malaysia, terutama orang Melayu tempatan. Hal ini tentulah tidak mungkin dalam era negara-bangsa (nation-state) seperti sekarang. Sebagai sebuah negara-bangsa Malaysia yang menjadi kepunyaan rakyatnya yang terdiri daripada etnik 
Melayu, Cina, India, Orang Asli, dan Bumiputera Sabah serta Sarawak. Umumnya, orang lain yang menumpang hidup di sini berstatus pendatang.

Orang Patani diaspora bukan sahaja mengalami masalah dipandang serong oleh masyarakat setempat, malah menganggap mereka telah dijadikan mangsa diskriminasi. Hal ini merumitkan lagi persoalan identiti dalam diri mereka, terutama generasi muda yang mahukan layanan yang sama seperti yang diperoleh oleh rakyat Malaysia. Persoalan inilah yang dihadapi oleh seorang watak dalam cerpen "Ke Negeri Impian" (2012) oleh Isma Ae Mohamad:

Ketika memasuki tingkatan empat, dia memahami apa itu diskriminasi mengikut pemahamannya. Dia tidak dibenar memasuki kelas aliran sains. Kata-kata seorang cikgu masih berdengung di telinganya, "Kelas sains hanya untuk rakyat Malaysia saja. Takut nanti awak akan kecewa besar bila tak dibenar duduki SPM selepas belajar bersungguh-sungguh. Baik masuk kelas aliran sastera sahaja."

Sebenarnya, nasihat guru dalam cerpen tersebut betul. Namun, kenyataan ini sukar diterima oleh seorang anak muda kaum pendatang yang mempunyai harapan yang tinggi mengawan daripada "negeri impiannya", Malaysia.

Seperti dipaparkan di atas, Malaysia ialah sebuah negara pelbagai kaum, dengan persoalan sosiopolitiknya yang tersendiri. Sifat kepelbagaian kaum ini ditambah lagi dengan kehadiran golongan pendatang telah mewujudkan sifat masyarakat majmuk yang sama dengan keadaan dunia pada abad ke-21 yang bersifat global. Hal ini selaras pula dengan pola sosial yang dikemukakan oleh Lee, iaitu pola manifestasi butik multi-budaya (boutique multicultural manifestation). Dalam pola sosial seperti inilah masyarakat Melayu Patani, terutama generasi diaspora yang terkemudian, merasakan diri mereka dilabelkan sebagai orang Melayu kelas kedua. Namun, yang baiknya mereka tidak mengalami proses asimilasi budaya di Malaysia secara paksa. Hal ini demikian kerana, kebudayaan mereka yang pada asasnya telah sedia serupa dengan kebudayaan orang Melayu Malaysia.

Status kewarganegaraan kini menjadi penanda umum tentang identiti seseorang. Terutamanya bagi orang yang selalu berpindah-randah antara negara. Orang Patani yang telah berhijrah ke Malaysia dan telah menganggapnya sebagai tanah air kedua akan sentiasa berusaha untuk mendapatkan kerakyatan menjadi warganegara Malaysia. Mereka tidak mahu dianggap sebagai “pendatang', apatah lagi "pendatang haram". Walau bagaimanapun, selepas berlakunya pembentukan Malaysia sistem kewarganegaraan telah menjadi ketat. Hal 
ini menyebabkan mereka sering berasa kecil hati dan kecewa kerana sistem birokrasi kerajaan Malaysia yang "menyusahkan" mereka untuk mendapatkan kerakyatan di Malaysia. Rasa tersebut dapat dilihat melalui keluhan Nuriya dalam cerpen "Gadis Tomyam" (2012, hlm.85) seperti berikut:

Nuriya hanya menjawab, "Belum. Tiada rezeki." Kadangkala ia jawab, "Tiada jodoh lagi." Kalau boleh dia mahu menjawab, "Sudah habis borang diisi. Ibu sudah letih bertemu orang itu, orang ini. Muak dah dengar janji itu, janji ini yang keluar dari mulut orang politik. Kalau boleh mahu saja aku terjah Menteri Dalam Negeri!"

Melalui petikan tersebut, jelas terpancar rasa kekecewaan orang Melayu diaspora yang gagal untuk mendapatkan status kewarganegaraan Malaysia. Hal ini sedemikian kerana, status kedudukan mereka di tempat baharu tidak akan terjamin selagi tidak memiliki dokumen rasmi. Pihak penguat kuasa pada bila-bila masa sahaja boleh menahan mereka. Keperihalan ini ada dicoretkan oleh pengarang melalui watak "aku" dalam cerpen "Ke Negeri Impian" (2012) seperti petikan di bawah:

Ketika bas berhenti di pemeriksaan polis tak jauh dari sempadan, saat itu dia berharap polis yang sedang melakukan pemeriksaan kad pengenalan penumpang segera datang menangkapnya. Tangkaplah aku, tangkaplah aku, tangkaplah aku, begitulah dia kata batinnya. Semoga dengan penangkapannya, derita kewarganegaraan yang ditanggungnya ini berakhir. ${ }^{6}$

Oleh itu, dapat dilihat bahawa isu kerakyatan telah menjadi perkara yang paling dirisaukan oleh kelompok diaspora. Malah, isu ini telah mengganggu jiwa dan emosi diaspora ini hinggakan dalam petikan tersebut watak "aku" sanggup untuk ditangkap bagi menamatkan penderitaannya dan tidak perlu lagi memikirkan tentang kewarganegaraan.

Dalam pencarian identiti, semangat kebangsaan turut bermain dalam jiwa masyarakat Melayu Patani diaspora. Secara kebiasaannya, generasi pertama diaspora tidak mementingkan semangat kebangsaan di tempat baharu kerana penghijrahannya bermatlamatkan pencarian hidup yang lebih baik. Golongan ini lebih peka terhadap "semangat" budaya yang berkiblatkan negeri Patani. Namun, semangat ini berbeza kepada generasi diaspora terkemudian. Generasi ini telah menganggap Malaysia sebagai tanah airnya jua. Mereka hanya dilahirkan di Patani, tetapi dibesarkan di Malaysia dan ada juga yang lahir di Malaysia. Faktor persekitaran telah merubah pandangan 
dunianya. Dilema akan semangat kebangsaan ini ada diungkapkan oleh Isma Ae Mohamad (2012) melalui watak "aku" dalam cerpen "Ke Negeri Impian" adalah seperti yang berikut:

Dia merenung ke seberang, ke Thailand. Mengapalah aku tak membesar di sana? Dia akui bahasa Thainya makin teruk. Dia mengalih pandangan semula ke bendera Malaysia yang sedang berkibar-kibar, dia merasa meskipun dia tak memiliki kad pengenalan Malaysia, hatinya telah anggap dirinya sebagai warganegara Malaysia. ${ }^{7}$

Maka, dapat diakui bahawa orang diaspora terutama generasi yang terkemudian berasa bahawa diri mereka sebahagian daripada warga tempat yang diduduki walaupun tidak mempunyai kerakyatan. Hal ini demikian kerana, mereka telah dibesarkan dengan persekitaran tempat baharu sejak kecil lagi. Di tempat baharu ini, segala pengalaman dan liku-liku hidup telah mereka harungi. Mereka menyayangi negara ini seperti yang dirasakan oleh rakyat tempatan. Malah, perasaan kecintaan mereka mungkin melebihi rakyat tempatan kerana mereka memahami erti menjadi "rakyat yang sah" dan keadaan negara asal yang masih bergolak.

Selepas dianalisis keseluruhan cerpen Isma Ae Mohamad ini, didapati pola ketiga yang dikemukakan oleh Lee, iaitu politik identiti transisi atau transitional/ transformational identity politics, sememangnya wujud dalam masyarakat Melayu Patani diaspora. Pola ini menjelaskan bahawa akan berlaku transformasi identiti kepada generasi penghijrah yang terkemudian akibat faktor ruang dan masa. Dalam kes ini, masyarakat Melayu Patani diaspora generasi terkemudian secara tidak sedar mulai menyatukan diri mereka dengan semangat kebangsaan di Malaysia walaupun belum cukup membentuk identiti kebangsaan dalam diri mereka. Malah, Malaysia juga telah dianggap sebagai tanah air mereka. Oleh yang demikian, akan wujud integrasi sosial antara mereka dengan masyarakat majmuk Malaysia yang lain.

\section{KESIMPULAN}

Pembentukan dan pengekalan identiti amat penting bagi sesuatu kelompok etnik dan kaum bagi meneruskan kelangsungan sesuatu budaya. Masyarakat Melayu Patani didapati menghadapi dasar asimiliasi budaya yang cuba menghakis identiti mereka di Selatan Thailand. Namun, atas kekentalan jati diri, usaha tersebut tidak berjaya secara keseluruhannya. Walau bagaimanapun, desakan politik dan ekonomi tetapi menggalakkan masyarakat 
Melayu Patani untuk berhijrah ke Malaysia dan membentuk masyarakat diaspora tersendiri. Di Malaysia, masyarakat diaspora ini dipandang serong sehingga menimbulkan perbezaan kelas sosial selain identitinya seakan-akan diperlekeh kerana faktor perbezaan negara. Situasi ini demikian, kerana masyarakat Malaysia telah membina identiti kebangsaan melebihi identiti bangsa. Kesannya, masyarakat Melayu Patani diaspora mengalami sikap rendah diri dan berusaha membentuk identiti yang bersesuaian dengan etnik Melayu Malaysia.

Selain itu, didapati bahawa ketiga-tiga pola sosial diaspora oleh Regina Lee memang terdapat dalam masyarakat Melayu Patani diaspora. Pola sanjungan terhadap tanah air (idealization of homeland) sememangnya ada dalam karya Isma Ae Mohamad. Watak diaspora digambarkan merindui tanah airnya dan terkenangkan keagungan silam bangsanya. Pola sosial yang berkaitan dengan manifestasi butik multibudaya (boutique multicultural manifestation) pula dapat dilihat pada pembentukan masyarakat majmuk melalui pemindahan masyarakat Melayu Patani. Pola transisi (transitional/ transformational identity politics) pula dapat dirujuk kepada krisis bersama pencarian identiti di tempat baharu yang dipaparkan melalui pelbagai nukilan jalan cerita. Karya oleh Isma Ae Mohamad sememangnya sangat berkait rapat dengan pengalaman beliau sebagai manusia diaspora. Rangkuman keseluruhan cerpen dalam kajian ini memperlihatkan pandangan orang diaspora dari Patani tentang masa lalu dan masa kini kehidupan mereka.

\section{PENGHARGAAN}

Makalah berasaskan Geran RUI(Universiti Sains Malaysia) bertajuk "Warisan Patani Dalam Sastera, Budaya dan Media" (2012-2016) yang diketuai oleh Prof. Dato Seri` Dr. Md Salleh Yaapar.

\section{NOTA}

1. Spivak, Gayatri Chakravorty. (2012). "What Isn't Migrant Literature?" http://themigrationist. net/2012/12/13/what-isnt-migrant-literature/. Dicapai pada 7 Januari 2014.

2. Ejaan ini adalah mengikut ejaan rasmi pertubuhan badan tersebut.

3. http://www.utusan.com.my/utusan/Sastera/20121223/sa_01/Ke-negeri-impian. Dicapai pada 3 Januari 2013.

4. http://www.utusan.com.my/utusan/Sastera/20121223/sa_01/Ke-negeri-impian.Dicapai pada 3 Januari 2013.

5. http://www.utusan.com.my/utusan/Sastera/20121223/sa_01/Ke-negeri-impian. Dicapai 
pada 3 Januari 2013.

6. http://www.utusan.com.my/utusan/Sastera/20121223/sa_01/Ke-negeri-impian. Dicapai pada 3 Januari 2013.

7. http://www.utusan.com.my/utusan/Sastera/20121223/sa_01/Ke-negeri-impian. Dicapai pada 3 Januari 2013.

\section{RUJUKAN}

Ali Ahmad. (1994). Pengantar pengajian kesusasteraan. Kuala Lumpur. Dewan Bahasa dan Pustaka.

Bolaffi, Guido, Bracalenti, Raffaele, Braham, Peter H. \& Gindro, Sandro (ed.). (2003). Dictionary of race, ethnicity and culture. London: SAGE Publications.

Cohen, Robin. (2008). Global diaspora: An introduction. Oxon: Routledge.

http://keptanbp.blogspot.com/2013/10/pengurusan-murid-bukan-warganegara.html.

Tarikh capaian pada 18 Februari 2014.

Isma Ae Mohamad. (Jun 2011). "Perjalanan ke sebelah sana". Muslimah. Kuala Lumpur: Dian Darulnaim.

Isma Ae Mohamad. (Februari 2012). "Gadis tomyam”. Aniqah. Kuala Lumpur: MMP Communications Sdn Bhd.

Isma Ae Mohamad. (2012). “Ke Negeri Impian”. http://www.utusan.com.my/utusan/ Sastera/20121223/sa_01/Ke-negeri-impian. Capaian pada 19 September 2013. Isma Ae Mohamad. (Julai 2013). "Rindu Cerita Nenek". Dewan Budaya. Kuala Lumpur: Dewan Bahasa dan Pustaka.

Lee, Regina. (2004). "Theorizing diasporas: Three types of consciousness." Robbie B.H. Goh dan Shawn Wong (eds.). Asian diasporas: Cultures, identities, representations. Aberdeen: Hong Kong University Press.

Nik Anuar Nik Mahmud. (2011). Mencari perdamaian di Asia Tenggara: Merungkai konflik di Selatan Thailand. Bangi: Institut Alam dan Tamadun Melayu (ATMA) Universiti Kebangsaan Malaysia.

S.S. Shashi. (2007). International encyclopaedia of Social Science. Volume 5. New Delhi: Anmol Publications.

Shamsul A.B. (2007). Reconnecting "the nation" and "the state": The Malaysian Experience. Abdul Rahman Embong(ed.). Rethinking ethnicity and nationbuilding: Malaysia, Sri lanka and Fiji in comparative perspective. Kajang: Persatuan Sains Sosial Malaysia.

Spivak, Gayatri Chakravorty. (2012). "What isn't migrant literature?" http:// themigrationist.net/2012/12/13/what-isnt-migrant-literature/. Capaian pada 7 Januari 2014.

Suttiporn Bunmak. "To be or not to be orang Siam among Patani Melayu migrant workers in tom yam restaurants in Malaysia." https://www.yumpu.com/en/ document/view/7753259/to-be-or-not-to-be-orang-siam-among-patani-melayumigrant-. Tarikh capaian pada 5 Januari 2014. 
MALAY LITERATURE VOLUME 30 NUMBER 2 DECEMBER 2017

Thirumamani a/l Sundaraj. (2006). "Kesusasteraan diaspora India di Malaysia: Satu Kajian perbandingan tema identiti dalam karya pilihan bahasa Tamil dan bahasa Inggeris.” Disertasi untuk keperluan ijazah sarjana. Universiti Sains Malaysia, Pulau Pinang.

Received: 03 October 2017

Accepted: 27 October 2017 